\title{
UMA INSTITUIÇÃO NÃo RECONHECIDA: O Comitê de Ética da Polinésia Francesa
}

\author{
A NO RECOGNIZED INSTITUTION : \\ THE FRENCH POLYNESIA ETHICS COMMITTEE
}

$\left.\operatorname{Marc} J J_{1}\right)\left(111^{(*)}\right.$

\section{RESUMO}

Localizada cerca de 17.500 quilômetros da França, a Polinésia Francesa permanece desconhecida até para a maioria dos franceses, sendo que, são numerosos aqueles que nem sequer sabem que não se trata mais de um Território Ultramarino (em francês, Territoire d'outre-mer - TOM), categoria suprimida pela lei constitucional de 28 de março de 2003, mas sim de um Coletivo Ultramarino (em francês, Collectivité d'outre-mer - COM)(1). Nesse contexto, não é surpreendente que o Comitê de Ética da Polinésia Francesa não seja objetivo de nenhum estudo e que seja, mais freqüentemente, totalmente ignorado. Dessa maneira, este trabalho tem o objetivo de completar esta lacuna e de apresentar esta instituição da maneira mais completa, iniciando com o exame de sua organização e, em seguida, de suas atribuições.

\section{Palavras-chave}

Ética; Polinésia Francesa; Saúde.

(*) Professor de Direito Público da Universidade de Nantes e antigo membro do Comitê de Ética da Polinésia Francesa. E-mail: marc_joyau@yahoo.fr. Recebido em 10.1.07. Aprovado em 4.3.07.

(1) E não um país ultramarinho (em francês, Pays d'outre-mer - POM), como poderia fazer pensar o texto do artigo 1, alínea 2, da lei orgânica de 27 de fevereiro de 2004, a qual qualifica a Polinésia Francesa como "pais ultramarinho ao seio da República". Com efeito, o Conselho Constitucional precisou que esta denominação "não tem nenhum efeito legal" (décis. n. 2004-490 DC du 12 février 2004, consid. n. 13). Ver a esse respeito: JOYAU, M. Les anamorphoses de l'autonomie de la Polynésie française, L'homme, ses territoires, ses cultures. Mélanges offerts à André-Hubert Mesnard (J. Fialaire et E. Mondielli, Dir.), Paris: LGDJ 2006, p. 265, spéc. pp. 267-268. 


\section{ABSTRACT}

Located about 17.500 kilometers of France, French Polynesia remains unknown for the majority of the Frenchmen. They are several of them that do not know that it was not treated anymore as an Overseas Territory, category suppressed for the constitutional law of March 28, 2003. Nowadays, it is a Collective Overseas. In this context, it is not surprising that the French Polynesia Committee of Ethics is not objective of studies. Indeed, more frequently, it is totally ignored. In this way, this work has the objective of filling this gap by presenting this institution. At first, it will investigate its organization and then its attributions.

\section{Key words}

Ethics ; French Polynesia; Health.

\section{ORGANIZAÇÃO}

Foi por meio de uma deliberação da Assembléia da Polinésia Francesa, de 18 de novembro de 1999, que o Comitê de Ética da Polinésia Francesa (em francês, Comité d'éthique de la Polynésie française - CEPF) foi criado. Mesmo sendo este comitê relativamente recente ${ }^{(2)}$, assim como suas atividades (o primeiro decreto foi promulgado em 11 de outubro de 2001), sabe-se relativamente pouco sobre a origem desta instituição. Parece que foi a Liga dos Direitos Humanos da Polinésia(3), tradicionalmente preocupada com as questões de saúde desta região, que teve a idéia de criar o Comitê. Seja qual for sua origem, para melhor compreender o lugar desta instituição dentro da regulamentação de ética da Polinésia Francesa é necessário se debruçar sobre sua composição e funcionamento.

\subsection{Composição}

Diferentemente do Comitê Consultivo Nacional de Ética para as Ciências da Vida e da Saúde (CCNE, sigla em francês para Comité consultatif national d'éthique pour les sciences de la vie et de la santé) que, incluindo

(2) Ele foi instalado pelo Ministério da Saúde, no dia 18 de janeiro de 2001, na sede da direção de saúde.

(3) Ver ainda o recente Relatório 2005 (não publicado, até o momento) da Liga Polinésia de Direitos Humanos, intitulado "Halte au Mépris", no qual a Liga preconisa que "a saúde na Polinésia tornouse uma competência de Estado, em razão de uma 'degradação' e de uma 'disfunção' dos serviços de saúde". 
seu presidente, é formado por 39 membros divididos em três categorias ( 5 pessoas das áreas da família, filosofia e religião; 19 pessoas qualificadas e escolhidas em razão de seus interesses pelas questões éticas e 15 pessoas da área de pesquisa) $)^{(4)}$, os integrantes do Comitê de Ética polinésio não são objeto de nenhuma categorização.

Fixado inicialmente em 12, o número de integrantes deste Comitê de Ética foi aumentado para 15 por uma deliberação de 22 de janeiro de $2004^{(5)}$. Apesar da lista de membros ter sido determinada pelo Presidente da Polinésia Francesa, ele indica apenas um dos integrantes, o único escolhido "em razão de sua competência e de seu interesse pelas questões éticas"(6). Oito membros são designados pelos ministros, respectivamente da Saúde (dois representantes dos profissionais da saúde), da Pesquisa (um pesquisador), da Cultura, dos Assuntos Sociais e da Juventude (um representante da juventude), da Educação e da Promoção das Mulheres. Um integrante é escoIhido pelo Conselho da Ordem dos Médicos (que deve ser um médico) e outro pelo presidente da Universidade da Polinésia Francesa (que deve tratar-se de um professor-pesquisador da área de Direito). Enfim, a indicação dos quatro membros restantes escapa a todos os enquadramentos regulamentares. Tratam-se de representantes das igrejas evangélica e católica, da Liga de Direitos Humanos da Polinésia Francesa e da Academia Taitiana.

Muitos ensinamentos podem ser tirados desse modo de indicação. De qualquer maneira, é surpreendente que apenas um integrante (de 15) seja escolhido pelo seu interesse em questões éticas. No caso do CCNE, quase a metade (19 de 40) de seus membros são designados por essa razão. Sem dúvida, a explicação reside no fato de que a maioria das pessoas são selecionadas menos em razão de uma sensibildade às questões de ética e mais pela competência técnica (como é o caso do "professor-pesquisador" da área de Direito, ou jurista, designado pelo presidente da Universidade da Polinésia Francesa). Pela sua composição, o Comitê de Ética parece então ter sido concebido mais como um instrumento técnico de ajuda às decisões, do que como uma ferramenta de reflexão ética.

A falta de um enquadramento regulamentar na designação de três de seus membros conduz, no entanto, a um equilibrio dessa visão funcionalista do Comitê de Ética. Assim, enquanto os representantes das áreas da família, filosofia e religião do CCNE são em número de cinco e são designados pelo Presidente da República, os dois representantes das igrejas evangélica e católica e o representante da Liga de Direitos Humanos não são indicados

(4) Art. L. 1412-2 do Código da Saúde Pública, na redação editada da Lei n. 2004-800, de 6 de outubro de 2004 , relativa à bioética.

(5) Deliberação n. 2004-13 APF de 22 janeiro de 2004 que modifica a deliberação n. 99-209 APF de 18 novembro de 1999 sustentando a criação de um Comitê de Ética da Polinésia Francesa (art. 1, I) (JOPF de 29 janeiro de 2004, p. 305).

(6) Art. 2, al. 1 da deliberação de 18 de novembro de 1999. 
pelo Presidente da Polinésia, mas, pelos seus pares. Observa-se, então, que não apenas estas áreas são, proporcionalmente, mais importantes no Comitê de Ética polinésio (três de 15 , ou seja, $20 \%$ do total) e também que há uma vontade muito clara, por parte dos poderes públicos polinésios, de não intervir no funcionamento, procedendo a designação de integrantes que os representem no Comitê de Ética ${ }^{(7)}$. Os lugares reservados aos domínios familiares, filosóficos e religiosos neste Comitê se revelam ser relativamente conseqüentes.

Por outro lado, desde a deliberação de 22 de janeiro de 2004, o Comitê de Ética comporta um representante da Academia Taitiana(8). Aqui, a preocupação ética não é resultado de uma falta de enquadramento regulamen$\operatorname{tar}^{(9)}$, mas, de uma consideração com a cultura polinésia. De fato, a tradução para o taitiano das decisões e recomendações do Comitê estão na origem das dificuldades, notadamente a tradução da expressão "doença genética". Se "doença hereditária" se traduz como ma'i tupuna(10) (que significa doença ancestral, no sentido de muito antiga), essa expressão não podia ser usada para traduzir "doença genética". A palavra Tupuna (que siginifica ancestral) tem, na verdade, uma conotação afetiva muito forte. Desde então, dificilmente pode-se conceber, na Polinésia Francesa, a admissão que Tupuna pudesse transmitir qualquer tipo de mal, como, por exemplo, uma doença ${ }^{(11)}$. Indo além das considerações sobre as dificuldades técnicas em traduzir para o taitiano os trabalhos do Comitê de Ética (atividade que continua a ser realizada por um serviço de tradução exterior ao Comitê(12)), foi, então, uma preocupação de ordem ética que previu a presençãade um representante da Academia Taitiana no Comitê.

\subsection{Funcionamento}

O Comitê de Ética da Polinésia Francesa pode ser acionado pelo governo e pela Assembléia polinésia, mas, também, por um estabelecimento público ou privado, uma fundação e mesmo uma associação desde que,

(7) De qualquer maneira, seria um erro grave concluir que a religião e o funcionamento das instituições tenham existências separadas. Ver JOYAU, M. Les leçons des statuts spéciaux d'Outre-Mer: le cas de la Polynésie française, Liberté de culte, laïcité et collectivités territoriales (J. Fialaire, Dir.), Paris: Litec 2007, p. 199.

(8) Esta Academia foi criada pela Deliberação n. 72-92, de 2 de agosto de 1972 (www.farevanaa.pf).

(9) Este representante é de fato indicado pela Academia Taitiana.

(10) Académie tahitienne, Dictionnaire Tahitien-Français. Fa'atoro parau Tahiti-Farani, Académie tahienne-Fare vana'a 1999, p. 239.

(11) Consultada sobre esta questão, a Academia Taitiana propôs, "após a consulta dos acadêmicos", de traduzir "doença hereditária" por ma'i tupuna e "doença genética" por ma'i 'ihitene, realizando assim uma obra de criação para que a lingüa polinésia pudesse acompanhar a evolução da vida moderna e de suas técnicas (correio eletrônico em resposta, datado de 28 de fevereiro de 2006).

(12) V. infra, B. 
estes últimos, tenham por objetivos principais a pesquisa, o desenvolvimento médico-tecnológico, a promoção e proteção da saúde ${ }^{(13)}$. Na prática, até o momento, das 22 decisões tomadas, os órgãos oficiais da Polinésia Francesa acionaram o Comitê em 5 recursos ${ }^{(14)}$, o que significa que a coletividade territorial polinésia recorre pouco a este comitê. Todas as demais decisões foram tomadas diante de consultas do Centro Hospitalar Territorial (8), do Instituto Louis Malardé(15) $(7)$ ou da Universidade da Polinésia Françesa (2). O Comitê dispõe, igualmente, de um poder de se auto consultar ${ }^{(16)}$ mas, ele jamais o exerceu(17).

A freqüência das reuniões é regulamentada a um mínimo de duas por ano ${ }^{(18)}$ mas, na prática, essas reuniões são mensais. As convocações e a pauta são decididas pelo presidente, eleito pelos membros do próprio Comitêe ${ }^{(19)}$.

A instrução dos documentos se opera de maneira individual e coletiva. Cada membro do Comitê recebe, mais freqüentemente anexos à convocação, os documentos relacionados às questões inscritas na pauta do dia. Por outro lado, os responsáveis dos projetos submetidos por decreto são convidados pelo Comitê para apresentar as informações necessárias relacionadas às questões éticas de seus projetos. Para estas audições, o Comitê de Ética pode convidar "todas as pessoas que julgar úteis"(20).

Inicialmente, o Comitê somente pode deliberar se metade de seus integrantes estiverem presentes. Este quórum foi reduzido para sete membros (de 15)(21), provavelmente em razão de um absenteísmo recorrente, mesmo considerando-se como regular a participação dos integrantes ${ }^{(22)}$. Por outro lado, a definição de decretos é feita com maioria dos membros presentes ${ }^{(23)}$. Porém, é preciso destacar que são, em geral, unânimes $(77,27 \%)$.

(13) Deliberação n. 99-209 APF, de 18 de novembro de 1999 (art. 4, al. 1 et 2).

(14) Dentro do governo, apenas os ministros da Saúde (4) e da Cultura, Ensino Superior e da Pesquisa (1) acionaram o Comitê de Ética. A Assembléia da Polinésia Francesa nunca o fez.

(15) Dotado do status de estabelecimento público de caráter industrial e comercial (sigla em francês EPIC) em $1^{\circ}$ de janeiro de 2001, este instituto trabalha para a preservação da saúde, da higiene pública e do ambiente da Polinésia. (Deliberação n. 2000-114 APF, de 28 setembro de 2000).

(16) Deliberação n. 99-209 APF, de 18 de novembro de 1999 (art. 4, al. 3).

(17) As três recomendações formuladas pelo Comitê não mencionam o autor da consulta, mas seu conteúdo não permite concluir que houve um acionamento feito pela própria instituição, artigo 4 , alinea 3.

(18) Deliberação n. 99-209 APF, de 18 de novembro de 1999 (art. 5, al. 1er).

(19) Deliberação n. 99-209 APF, de 18 de novembro de 1999 (art. 2, al. 2).

(20) Deliberação n. 99-209 APF, de 18 de novembro de 1999 (art. 5, al. 4). É assim, por exemplo, que uma reunião foi exclusivamente consagrada, em 16 de fevereiro de 2004, a um encontro com P. L. Fagniez, relator da lei de bioética da Assembléia Nacional.

(21) Deliberação n. 2004-13 APF, de 22 de janeiro de 2004 (art. 1er, III).

(22) Apenas três sessões não se realizaram em razão de quórum insuficiente. A única modificação feita ao regulamento interno do Comitê de Ética teve relação com o relaxamento das condições que permitem declarar um integrante demissionário da instituição.

(23) Deliberação n. 99-209 APF, de 18 de novembro de 1999 (art. 5, al. 3). 
Da mesma forma, destaque-se que nenhum voto é feito sem que cada integrante tenha sido convidado a apresentar seu ponto de vista, prática diferente no caso do Comitê Consultivo Nacional de Ética para as Ciências da Vida e da Saúde (CCNE).

A maneira como as decisões são emitidas pelo Comitê de Ética merece um detalhamento. Em efeito, diferentemente das decisões do CCNE que são relativamente longas e desenvolvem uma reflexão e argumentos éticos sobre um determinado assunto, as decisões do Comitê de Ética da Polinésia Francesa se caracterizam por sua brevidade e, salvo exceções ${ }^{(24)}$, por uma total falta de motivação. Os decretos são "desfavoráveis" ou " favoráveis" e, neste último caso, eles são, freqüentemente, acrescidos de reservas. A partir de um exame atento a estas reservas, destacam-se quatro situações constantes:

1) o consentimento livre, expresso e claro do doador ou da pessoa que será objeto de um estudo biomédico deve ser obtido previamente pelo iniciador da pesquisa;

2) cada paciente deverá ser informado, em seu idioma e de uma maneira compreensível, dos resultados da pesquisa, exceto por recusa expressa do mesmo;

3) o material biológico deverá ser destinado apenas à pesquisa prédeterminada, devendo ser destruído ao final da mesma;

4) a identidade das pessoas físicas e jurídicas responsáveis pelo estudo deve ser conhecida.

As decisões relativas às transfusões de órgãos e tecidos têm condições próprias:

1) toda a retirada de órgãos e tecidos somente pode ser feita quando diagnosticada a morte encefálica dos doadores;

2) toda doação deverá respeitar o princípio do anonimato;

3) nenhuma transação financeira poderá ser exigida como contrapartida a uma doação.

O conteúdo dessas condições pode surpreender, na medida em que, na metrópole (França) elas figuram nas disposições do Código de Saúde Pública ${ }^{(25)}$. Porém, se estas reservas são formuladas pelo Comitê de Ética da Polinésia Francesa, isso acontece porque, em virtude do princípio de "especialidade legislativa", as disposições do Código de Saúde Pública não se

(24) V. infra, II.

(25) V. especialmente todo o Título II ("Recherches biomédicales") do Livro $1^{\circ}$ ("Protection des personnes en matière de santé") e III ("Organes") e IV ("Tissus, cellules, produits du corps humain et leurs dérivés") do Livro II ("Don et utilisation des éléments et produits du corps humain") do Code de la santé publique (Código da Saúde Pública). 
aplicam na Polinésia Francesa. No estado atual do Direito Positivo, é o Comitê de Ética polinésio que assegura uma regulação ética em seu território. Os órgãos competentes da coletividade territorial falharam em regulamentar esta questão(26).

As recomendações e decisões são públicas ${ }^{(27)}$. Sobre esta questão de publicidade, as disposições regulamentares não são mais precisas. O regulamento interno do Comitê prevê (art. 15) que as decisões e recomendações sejam redigidas em Francês e em Taitiano(28), que sejam publicadas no Jornal Oficial da Polinésia Francesa e divulgadas ao público pelos meios de comunicação ${ }^{(29)}$.

Enfim, todos os trabalhos do Comitê e o conjunto de suas atividades são objeto de um relatório anual para os presidentes da Polinésia Francesa, da Assembléia Nacional, do Conselho Econômico, Social e Cultural, assim como para os Ministérios da Saúde e da Pesquisa ${ }^{(30)}$.

Os demais detalhes do funcionamento do Comitê de Ética da Polinésia Francesa são fixados pelo seu regulamento interno(31), em sua grande parte respeitado(32).

\section{ATRIBUIÇÕES}

As questões submetidas ao Comitê de Ética são de inegável importância. Se algumas podem parecer anedóticas em uma perspectiva de princípios éticos ${ }^{(33)}$, a maioria delas permite ao Comitê desenvolver uma verdadeira

(26) O Comitê chama a atenção das autoridades sobre este ponto em um recurso, e de maneira bastante indireta, em sua decisão n. 21 ("As questões que estão na origem desta prerrogativa a conduzem, em último lugar : ... a chamar a atenção do conjunto de autoridades públicas sobre o fato de que é dever de cada uma delas de velar, no campo de suas competências, pelo respeito da lei e das exigências éticas relacionadas por esse comitê").

(27) Deliberação n. 99-209 APF, de 18 de novembro de 1999 (art. 6, al. 2).

(28) A redação em Taitiano é assegurada pelo Serviço (territorial) de tradução e interpretação, dentro de um prazo que varia de 10 dias a três meses.

(29) Na prática, elas não são publicadas no Jornal Oficial e apenas as decisões mais importantes são divulgadas pela imprensa local.

(30) Deliberação n. 99-209 APF, de 18 de novembro de 1999 (art. 6, al. 1er). Um relatório (único) foi estabelecido nos anos 2001 (uma parte) e 2002. Um outro relatório foi estabelecido em 2004. Parece que 2003 não foi objeto de nenhum relatório anual.

(31) Deliberação n. 99-209 APF, de 18 de novembro de 1999 (art. 5, al. 5).

(32) Enfim, para completar, é necessário acrescentar que os recursos humanos e materiais do Comitê são extremamente reduzidos. O secretariado é assegurado pela Direção de Saúde (por uma só pessoa, responsável pelo escritório de negócios jurídicos da Direção de Saúde). Os integrantes do Comitê têm a disposição uma "documentação" (pouco abundante). O Comitê não conta com nenhum orçamento.

(33) Tal é, sem dúvida, o caso do protocolo de pesquisa relativo à avaliação da eficácia da prática regular do karatê para a melhoria da qualidade de vida e das aptidões físicas de um grupo de qüinquagenários (Decisão n. 16, de 30 de outubro de 2003). 
regulação neste campo. Uma decisão merece, entretanto, uma atenção especial: a decisão n. 12 relativa ao estabelecimento de um banco de DNA, a qual é sintomática do caráter ambíguo deste Comitê.

\subsection{Edição de reparações éticas}

De maneira pontual, notadamente pela formulação de reservas específicas, muitas decisões permitem ao Comitê propor verdadeiras reparações éticas.

No que concerne à atividade médica propriamente dita, o Comitê foi assim instruido:

- para recomendar, em benefício dos agentes coletores ou de todas as pessoas que participam da coleta de mosquitos (e não em benefício dos pacientes), que seja obtido, por meio de um formulário individual, livre consentimento, expresso e claro sobre o risco de transmissão da dengue (Decisão n. 07);

- para recomendar que os pacientes sejam advertidos de seu direito de se retirar, a qualquer momento, da pesquisa (Decisão n. 09 ${ }^{(34)}, 23$ e 24);

- a lembrar que os médicos não devem ser submetidos a nenhuma pressão, notadamente de caráter econômico (Decisão n. 10)(35).

Qualquer decisão permite então melhor entender o caráter "endêmico" da ética na Polinésia Francesa. Tal é o caso de decisões que recomendam a tradução em idioma Taitiano(36) do formulário de consentimento do paciente ou que são favoráveis a esta reserva ${ }^{(37)}$; ou a decisão favorável, sob reserva, que o estudo apreciado suprima "toda referência étnica em benefício de uma referência geográfica"(38).

Este ponto apresenta uma importância capital. De fato, numerosos estudos, em especial os genéticos ${ }^{(39)}$, são apresentados como se devessem ser realizados em função da origem étnica, sendo que as pessoas envolvidas são mais freqüentemente qualificadas de polinésias ou taitianas. Entretanto,

(34) Em razão, neste caso específico, ao fato de que a realização de um determinado estudo impõe pesados entraves aos pacientes (uso de aparelhos, visitas médicas frequentes etc).

(35) A decisão especifica que "sua convenção com o laboratório deve ser submetida por decisão ao conselho da ordem dos médicos. As remunerações não serão calculadas de maneira proporcional ao número de pacientes, de serviços ou de produtos prescritos".

(36) E, no caso de estudos "que abange vários arquipélagos ... se possivel dentro de um idioma compreendido pelo paciente" (Decisão n. 24).

(37) Decisões ns. 05, 07, 11, 13, 15 a 19 e 22 a 24.

(38) Decisões ns. 17.

(39) Pesquisas dos genes suscetíveis à obesidade, à diabetes de tipo 2, à sindrome de Alport (nefropatia, afecção que atinge o rim - hereditária, freqüentemente associada a uma surdez e anomalias oculares), ao câncer da tiróide, aos problemas cardiacos e aos problemas bipolares e esquizofrênicos. 
se do ponto de vista etnológico, compreende-se evidentemente a referência à noção de etnia (o mesmo em uma abordagem biológica ${ }^{(40)}$ ou jurídica ${ }^{(41)}$, na qual pode-se entender a referência ao conceito de raça), a terminologia torna-se prudente quando se trata de correlacionar etnia e biologia. O risco está em estigmatizar uma população, dita "taitiana" ou "polinésia", com particularidades genéticas que podem ser vistas de uma maneira negativa. É sem dúvida por esta razão que o Comitê de Ética proferiu, por unanimidade, uma decisão desfavorável ao projeto de pesquisa de estudo genético dos problemas bipolares e esquizofrênicos no ambiente insular ${ }^{(42)}$.

Com essas duas últimas decisões, observa-se uma passagem da atividade reguladora do Comitê - no sentido de atividade normativa que consiste em editar as "regulamentações" (mais uma vez, os órgãos competentes da coletividade territorial falharam em exercer suas competências de regulamentação) - para uma atividade mais especificamente ética, que consiste em desenvolver uma reflexão e, caso apareça uma oportunidade, em emitir um ponto de vista sobre o tema em estudo. Esta tendência se destacou, mais particularmente, em duas decisões do Comitê de Ética. Uma delas é relativa ao anteprojeto de deliberação da Assembléia da Polinésia que trata das modalidades de aplicação de dispositivos relacionados à interrupção voluntária da gravidez ${ }^{(43)}$.

A outra decisão é relativa a uma prática, desenvolvida desde 2001 por polinésios que fazem diálise na espera de um transplante renal, que consiste em viajar para a China para ser operado, durante um período de 10 a 15 dias, recebendo um rim que pode ser comprado de um doador vivo ou de um condenado à morte ${ }^{(44)}$. Nesta decisão, o Comitê não se declara nem favorável, nem desfavorável, ele exprime uma opinião(45).

Esta dualidade da atividade do Comitê de Ética se encontra formulada em termos sensivelmente diferentes, dentro das disposições regulamentares

(40) T. Monod, L'hippopotame et le philosophe, Actes Sud 1993 (spéc. p. 45 à 50 : "Les races d'Afrique").

(41) O preâmbulo da Constituição de 27 de outubro de 1946 proclama, em sua alínea $1^{\text {a }}$, que todo ser humano possui direitos inalienáveis e sagrados "sem distinção de raça". Quanto ao Código Penal, ele prevê numerosas infrações em razão de distinções feitas a partir da raça.

(42) Decisão n. 14. Esta posição foi adotada "considerando o impacto negativo que poderia ter este estudo sobre a comunidade, devido, principalmente às dificuldades de preservar a confidencialidade" e "apesar deste projeto de pesquisa ser objeto de estudo de outros trabalhos no mundo, o beneficio esperado deve ser balanceado com o impacto negativo".

(43) Decisão n. 06.

(44) Não parece, entretanto, que as execuções sejam realizadas para permitir o transplante (Les Nouvelles de Tahiti, 10 juin 2005, p. 10).

(45) É possivel também relacionar a esta tendência a Decisão n. 20, na qual o Comitê se declara desfavorável a um projeto de pesquisa em genealogia molecular que visa a constituir uma base de doadores "principalmente destinada a religar informações genéticas às linhas genealógicas escritas", pelo motivo que "este objetivo é contrário às regras da ética" (fórmula que pode-se considerar desastrada, na medida em que não se enxerga muito bem, a priori, quais seriam estas regras). 
que Ihe são aplicáveis. O art. $1^{\circ}$ da Deliberação de 18 de novembro de 1999, que prevê a criação do Comitê, dispõe, em sua alínea 2, que: "Este Comitê tem por missão emitir decisões e recomendações sobre problemas éticos surgidos em decorrência das novas tecnologias, das pesquisas e do progresso do conhecimento, nos campos da Biologia, da Medicina e da Saúde", e, em sua alínea 3, que: "ele emite decisões sobre todo projeto de pesquisa biomédica, que lhe é obrigatoriamente submetido." Nota-se que o texto impõe ao Comitê se pronunciar sobre a forma de "decisão" nesta última hipótese, mas, permite indistintamente o recurso a uma decisão ou a uma recomendação na primeira. Na prática, ainda que o Comitê tenha buscado estabelecer uma distinção entre as decisões e as recomendações ${ }^{(46)}$, é preciso reconhecer que ele não dá nenhuma importância a esta tipologia( ${ }^{(47)}$.

\subsection{Um papel, por vezes, ambiguo}

Questionado sobre esta questão pelo Ministério da Saúde, o Comitê de Ética da Polinésia Francesa emitiu, em 5 de junho de 2003, uma decisão favorável à criação de um banco de DNA na região: "sob a forma jurídica de um grupo de interesse econômico que garante sua independência", "dentro do respeito às regras deontológicas aplicáveis aos bancos de doadores de DNA" e "sob a reserva que o Comitê de Ética seja sistematicamente consultado para decisões favoráveis previamente à disponibilização de material genético no quadro de uma pesquisa". Por outro lado, nesta mesma decisão, o Comitê "recomenda que Ihe seja informado do conjunto do projeto" de criação deste banco.

Em resumo, após ter deliberado sobre o assunto em nove sessões ${ }^{(48)}$, o Comitê regulamentou uma questão que é objeto de uma volumosa e muito interessante decisão tomada pelo Comitê Consultivo Nacional de Ética para as Ciências da Vida e da Saúde (CCNE). Entretanto, como sublinha esta decisão do CCNE: "As atividades de coleção e tratamento de espécimes biológicas de origem humana e a oferta de informação daí resultante, mais particularmente da pesquisa genética, suscitam questionamentos éticos maiores". De fato, se os "biobancos" ou "biotecas" constituem uma

(46) Em seu primeiro relatório anual, pode-se encontrar: "Uma decisão é tomada no momento em que um projeto de texto regulamentar é considerado. Uma recomendação é formulada quando certos elementos visem a precisar as modalidades de um estudo ou de uma pesquisa em curso ou em projeto" (p. 2).

(47) Certas "Decisões" não comportam recomendações (ns. 05 e 21) e, entre as raras "Recomendações", uma delas não comporta uma decisão (ns. 03-1) ... mesmo em se tratando de um projeto de pesquisa biomédica.

(48) Esta foi uma decisão com várias deliberações. Freqüentemente, as decisões são tomadas após duas deliberações (13 casos). Três decisões necessitaram de três deliberações; quatro não necessitaram mais do que uma. Uma única decisão foi tomada após quatro deliberações. 
chance considerável para a pesquisa científica e geram importantes questões éticas, "ninguém ignora que a ciência não é apenas uma instituição social que se interessa por práticas de coleta de informações relativas aos componentes genéticos das pessoas. As seguradoras ou os serviços de interrogatórios policiais, por exemplo(49), são particularmente tocados por esse interesse' ${ }^{\prime 50)}$.

Não há intenção de fazer nenhuma apreciação crítica sobre a falta de posicionamento da decisão do Comitê de Ética da Polinésia Francesa. A referência sobre "regras deontológicas aplicáveis aos bancos de doadores de DNA" parece destacar mais um elemento de magia do que o realidade. Não existe verdadeiramente "regras deontológicas"(51) nesta matéria, uma vez que, segundo o Comitê: "o primeiro passo a ser dado é definir as obrigações comuns que regeram o estatuto do curador (conservador das espécimes e doações), o mesmo vale para o operador, seja público, privado ou uma parceria entre ambas as esferas." "(52) Por outro lado, dentro de um plano ético, é permitido não se deixar convencer da bem fundamentada posição que consiste em pretender "garantir a independência de um banco de DNA"(53).

Em compensação, a responsabilidade do Comitê de Ética sobre a questão jurídica e, mais precisamente, estatutária do banco de DNA merece um detalhamento. É incontestável que a criação de um banco de DNA supõe uma "passagem da ética para o direito"(54). Mas, como é destacado pelo CCNE, em sua decisão já citada: "Se a definição de um estatuto para o banco é o ponto de partida de uma resposta para as inquietudes, ele não é .... o problema mais difícil." ${ }^{255)} \mathrm{Em}$ outras palavras, sempre segundo o CCNE e faça-se justiça também segundo nossa opinião, é dever dos poderes públicos "de se responsabilizar pelo problema dos bancos e organizar seu regime juridico"s56).

Assim, pode-se considerar uma surpresa a posição do Comitê de Ética da Polinésia Francesa.

(49) Como não é possivel ignorar também as relações financeiras (direitos de propriedade intelectual, depósitos títulos ligados às pesquisas patrocinadas por bancos) relacionadas com a criação de um banco de DNA. (V. VII da Decisão n. 77, já citada).

(50) Decisão $n .77$, de 20 de março de 2003, sobre os problemas éticos colocados pelas coleções de material biológico e de doações de informação associadas : "biobancos", "biotecas", Les cahiers du CCNE n. 38, mars/avril 2004, p. 3.

(51) No código de deveres, os discursos sobre esses deveres [Le terme déontologie vient en effet "du grec deon (ce qu'il faut faire) et logos (discours)" (O. de Dinechin, M. Domergue, F.-X. Dumortier et L. Pareydt, Liberté, loi, morale, Assas éditions 1992, p. 114)].

(52) VII, 3 da Decisão citada.

(53) Em sua Decisão n. 77, o CCNE desenvolve, ao contrário, a idéia que "o banco deve ... ser declarado, eventualmente sujeito à autorização, em todo estado de causa supervisionada em seu funcionamento" (III).

(54) 8 da Decisão citada.

(55) III da Decisão citada, in fine.

(56) VIII da Decisão citada. 
Os termos da decisão do Comitê de Ética polinésio não permitem saber se a compreensão do ministro em cargo da Saúde implica, ou não, que esta consulta comporte igualmente a forma jurídica a ser dada ao banco, mas é razoável a dúvida. Como acreditar que os órgãos da coletividade territorial polinésios teriam desejado obter uma "consulta jurídica" de um Comitê que eles sabem bem não ter sido constituido com este objetivo e que não dispõe de competências jurídicas particulares? Em compensação, não é de se excluir que o Comitê de Ética polinésio tenha sonhado em formar um grupo de interesse econômico (em francês, groupement d'intérêt économique - GIE), imaginando garantir o bom funcionamento e, sobretudo, a independência do banco de DNA em face de todo poder político, administrativo ou econômico(57). A menos que não seja por influência de uma reflexão desenvolvida neste sentido pelos serviços (jurídicos?) desta coletividade territorial. Qualquer que seja a razão, o Comitê polinésio apodera-se de uma questão que destaca a competência da Polinésia Francesa em sua qualidade de $\operatorname{COM}$ e, não é certo que ele seja realmente competente, tanto no sentido de sua aptidão jurídica, como de seus conhecimentos técnicos.

Resta que a forma do GIE, condição de decisão favorável do Comitê à criação de um banco de DNA, terá conseqüência.

Procurando colocar em prática a decisão do Comitê de Ética, os serviços territoriais elaboraram um projeto de estatuto de um grupo de interesse econômico que foi submetido aos seus parceiros eventuais(58). Todos se recusaram se tornar membros do grupo (por razões juridicas), propondo uma colaboração com um banco de DNA, por convenção. Quanto ao Comitê de Ética polinésio, ele se pronunciou sobre três recursos (decisões 17, 18 e 23) de decisões favoráveis para projetos de pesquisas que necessitam de material genético, sob a condição de que os pesquisadores se comprometessem em controlar e descartar, ao fim do estudo, este material(59). O Comitê continua ${ }^{(60)}$, assim, a se opor a toda forma de estocagem, as quais podem, apesar de tudo, apresentar alguma vantagem, ao menos dentro de uma eventualidade de um novo estudo realizado ulteriormente pelos mesmos pesquisadores, sobre o mesmo assunto(61).

(57) Preocupação certamente fundamentada em A. W. du Prel, Banque d'ADN de Tahiti: étrange politique du gouvernement, TPM janvier 2001, p. 21.

(58) Associação Francesa contra as miopatias, Associação Genethon III, Instituto Louis Malardé, Universidade da Polinésia Francesa, Centro Hospitalar Territorial.

(59) Pelas Decisões ns. 17 e 18, o Comitê de Ética precisa que esta posição está ligada à "ausência de existência legal do banco de DNA na Polinésia Francesa".

(60) Recomendação n. 2.

(61) Confrontados com uma verdadeira situação de blocagem em virtude da vontade de colocar em prática a decisão do Comitê, os poderes públicos parecem se orientar em direção a uma solução que consiste em ligar este banco de DNA ao centro de transfusão sangüinea, um serviço da Direção de Saúde, ampliando suas missões. 
Concluindo, o Comitê de Ética da Polinésia Francesa não é tomado por uma forma exótica dos Comitês de Proteção das Pessoas (em francês, Comités de protection des personnes - $C P P)^{(62)}$, não somente porque ele não é dotado de personalidade jurídica ${ }^{(63)}$ e não emite decisão conforme ${ }^{(64)}$, mas, também porque sua missão consiste em dar "decisões sobre todo projeto de pesquisa biomédica que lhe é obrigatoriamente submetido" e "decisões e recomendações sobre os problemas éticos originados pelas novas tecnologias, a pesquisa e o progresso do conhecimento, dentro dos campos da Biologia, Medicina e Saúde"(65), sendo estas últimas confiadas na metrópole ao $\mathrm{CCNE}^{(66)}$.

O CCNE é qualificado como "autoridade independente" pelo art. L. 1412-2 do Código da Saúde Pública(67) e o Comitê de Ética da Polinésia Francesa como "organismo independente" pelo Art. 1, alínea 1a da Deliberação de 18 de novembro de 1999, já mencionada. Sem dúvida, é possível entender o Comitê polinésio como uma Autoridade Administrativa Independente local(68).

\section{REFERENCIAS}

ACADÉMIE TAHITIENNE, Dictionnaire Tahitien-Français. Fa'atoro parau Tahiti-Farani, Académie tahienne-Fare vana'a 1999.

LES CAHIERS DU CCNE n. 38, p. 3, mars/avr. 2004.

DINECHIN, O. de; DOMERGUE, M.; DUMORTIER, F.-X.; PAREYDT, L. Liberté, loi, morale. Assas Éditions, 1992.

(62) Estes comitês foram instituidos em lugar dos Comitês Consultivos de Proteção das Pessoas que participam de Pesquisa Biomédica (GAUDEMET, Y. Les comités consultatifs de protection des personnes dans la recherche biomédicale, CCPPRB Le Bilan juridique, JCP 1993-I-3653) pela Lei n. 2004-806 de 9 de agosto de 2004 relativa à política de saúde pública (S. Monnier, Les Comités de protection des personnes: l'émergence d'une nouvelle catégorie de personnes publiques spécialisées?, RDP 2005, p. 1519).

(63) Estes são os CPP (Art. L. 1123-1 do Código de Saúde Pública).

(64) Art. L. 1121-4 do Código de Saúde Pública (al. 1ㄹ: "A pesquisa biomédica não pode ser praticada que sob decisão favorável do Comitê de Proteção de Pessoas mencionado no artigo L. 1123-1 e sob a autorização da autoridade competente mencionada no artigo L. 1123-12").

(65) V. supra.

(66) "O Comitê Consultivo Nacional de Ética para as Ciências da Vida e da Saúde tem por missão decidir sobre problemas éticos originados pelos progressos do conhecimento nos domínios da Biologia, Medicina e da Saúde e de publicar recomendações sobre estes assuntos" (art. 23, al. 1" da Lei n. 94-654, de 29 de julho de 1994 relativa à doação e utilização de elementos e produtos do corpo humano, à assistência médica à procriação e ao diagnóstico pré-natal).

(67) Em sua redação editada da Lei n. 2004-800, de 6 de agosto de 2004 relativa à bioética.

(68) Sobre a objeção consiste em sustentar que uma Autoridade Administrativa Independente não seria mais do que uma instituição do Estado, ver: JOYAU, M. La régulation éthique en Polynésie française, CAPP 2006, n. 14, p. 32, spéc. p. 43-44. 
GAUDEMET, Y. Les comités consultatifs de protection des personnes dans la recherche biomédicale. CCPPRB Le Bilan juridique, JCP 1993-I-3653.

JOYAU, M. Les anamorphoses de l'autonomie de la Polynésie française. In: FIALAIRE, J. MONDIELLI, E. (Dir). L'homme, ses territoires, ses cultures: mélanges offerts à André-Hubert Mesnard. Paris: LGDJ, 2006.

Les leçons des statuts spéciaux d'outre-mer: le cas de la Polynésie française. In: FIALAIRE, J. (Dir.). Liberté de culte, laïcité et collectivités territoriales. Paris: Litec, 2007.

La régulation éthique en Polynésie française. CAPP, n. 14, 2006.

MONNIER, S. Les Comités de protection des personnes: l'émergence d'une nouvelle catégorie de personnes publiques spécialisées?, RDP, 2005.

MONOD, T. L'hippopotame et le philosophe. Actes Sud, 1993 (spéc. p. 45 à 50: "Les races d'Afrique").

\section{VERSÃO EM FRANCÊS}

\section{Une institution MÉconnue: \\ Le Comité d’Ethique de la Polynésie française}

$\operatorname{Marc~Joya\prime ^{(*)}}$

\section{ORGANISATION}

C'est par une délibération de l'assemblée de la Polynésie française du 18 novembre $1999^{(1)}$ que le Comité d'éthique de la Polynésie française a été créé. Bien que ce comité soit relativement récent ${ }^{(2)}$ et que son activité le soit encore davantage (le premier avis a été rendu le 11 octobre 2001), on sait relativement peu de chose sur l'origine de cette institution. II semblerait que ce soit à la Ligue des droits de l'homme de Polynésie, traditionnellement

(*) Maître de conférences de droit public à l'Université de Nantes; ancien membre du Comité d'éthique de la Polynésie française.

(1) Délibération n. 99-209 APF du 18 novembre 1999 portant création d'un Comité d'Éthique de la Polynésie française (JOPF du 25 novembre 1999, p. 2).

(2) Il a été installé par le ministre de la santé, le 18 janvier 2001, dans les locaux de la direction de la santé.

"3) V. encore récemment le Rapport 2005 (non publié) de la Ligue polynésienne des droits de I'homme: "Halte au Mépris", dans lequel la Ligue préconise "que la santé en Polynésie redevienne une compétence d'état" du fait d'une "dégradation" et du "dysfonctionnement" des services de soins. 
préoccupée par les questions de santé en Polynésie française ${ }^{(3)}$, que revienne l'idée de cette création. Quoiqu'il en soit, afin de mieux appréhender la place de cette institution dans la régulation éthique en Polynésie française, il est nécessaire de s'attacher à sa composition $(A)$ puis à son fonctionnement $(B)$.

\subsection{Composition}

A la différence du Comité consultatif national d'éthique pour les sciences de la vie et de la santé (CCNE) qui, si l'on excepte son président, comporte 39 membres répartis en 3 catégories [personnalités appartenant aux principales familles philosophiques et spirituelles (5); personnalités qualifiées choisies en raison de leur compétence et de leur intérêt pour les problèmes d'éthique (19) et personnalités appartenant au secteur de la recherche (15) $]^{(4)}$, les membres du CEPF ne font l'objet d'aucune catégorisation.

Initialement fixé à 12, le nombre de ces membres a été porté à 15 par délibération du 22 janvier $2004^{(5)}$. Si la liste des membres est fixée par arrêté du président de la Polynésie française, ce dernier n'en désigne qu'un, l'unique (!) membre choisi "en raison de sa compétence et de son intérêt pour les problèmes éthiques"(6). Huit membres sont désignés par les ministres, respectivement chargés de la santé (qui désigne deux "personnalités représentant les professions de santé"), de la recherche (qui désigne un "chercheur"), de la culture, des affaires sociales, de la jeunesse (qui désigne un "représentant de la jeunesse"), de l'éducation et de la promotion des femmes (qui l'un et l'autre désigne une "personnalité"). Un membre est désigné par le conseil de l'ordre des médecins (il doit s'agir d'un "médecin") et un autre par le président de l'université de Polynésie française (il doit s'agir d'un "enseignant-chercheur de droit"). Enfin, la désignation des quatre membres restant échappe à tout encadrement réglementaire. II s'agit des représentants de l'Eglise évangélique, de l'Eglise catholique, de la Ligue des droits de l'homme de Polynésie et de l'Académie tahitienne.

Plusieurs enseignements peuvent être tirés des modes de désignation adoptés. Tout d'abord, il est permis de s'étonner qu'une seule personnalité (sur 15) soit choisie en raison de sa compétence et de son intérêt pour les problèmes éthiques ... là où près de la moitié (19 sur 40) des membres du CCNE est choisie à ce titre. L'explication tient sans doute au fait que la majorité des personnalités choisies le sont moins en raison de leur sensibilité aux questions d'éthique, qu'en raison de leurs compétences techniques (tel est

(4) Art. L. 1412-2 du code de la santé publique, dans sa rédaction issue de la Loi n. 2004-800 du 6 août 2004 relative à la bioéthique.

(5) Délibération n. 2004-13 APF du 22 janvier 2004 modifiant la délibération $n$. 99-209 APF du 18 novembre 1999 portant création d'un comité d'éthique de la Polynésie française (art. 1 1er, I) (JOPF du 29 janvier 2004, p. 305).

(6) Art. 2, al. 1er de la délibération du 18 novembre 1999. 
manifestement le cas pour l' "enseignant-chercheur de droif", autrement dit le juriste, le spécialiste du droit, désigné par le président de l'université de Polynésie française). De par sa composition, le CEPF semble donc avoir été davantage conçu comme un instrument technique d'aide à la décision que comme un outil de réflexion éthique.

L'absence d'encadrement réglementaire de la désignation de trois de ses membres conduit pourtant à tempérer un peu cette vision très fonctionnaliste du CEPF Ainsi, alors que les personnalités appartenant aux principales familles philosophiques et spirituelles du C.C.N.E. sont au nombre de cinq et sont désignées par le Président de la République, les deux personnalités représentant les Eglises évangélique et catholique ainsi que le représentant de la Ligue des droits de l'homme de Polynésie ne sont pas désignées par le président de la Polynésie française, mais le sont en leur sein. On observe donc non seulement que la place faite à ces familles philosophiques et spirituelles est, proportionnellement, plus importante au sein du CEPF ( 3 sur 15 , soit $20 \%$ ) qu'au sein du CCNE ( 5 sur 40 , soit $12,5 \%$ ), mais encore qu'il y a une volonté très nette des pouvoirs publics polynésiens de ne pas s'ingérer dans leur fonctionnement en procédant à la désignation des membres qui les représentent au $\operatorname{CEPF}^{(7)}$ La place faite aux familles philosophiques et spirituelles dans cette institution s'avère donc être relativement conséquente.

Par ailleurs, depuis la délibération du 22 janvier 2004, le CEPF comporte une personnalité représentant l'Académie tahitienne ${ }^{(8)}$. Cette fois la préoccupation éthique ne résulte pas de l'absence d'encadrement. réglementaire ${ }^{(9)}$, mais de la prise en considération de la culture polynésienne. En effet, la traduction en tahitien des avis et recommandations du CEPF a été à l'origine de difficultés. II en a notamment été ainsi pour la traduction de l'expression "maladie génétique". Si "maladie héréditaire" se traduit par ma'i tupuna ${ }^{(10)}$ (qui signifie maladie ancestrale, au sens de maladie très ancienne), il ne pouvait en aller de même pour traduire "maladie génétique". Le mot Tupuna (qui signifie ancêtre) a en effet une connotation affective très forte. Dès lors, il est difficilement concevable, en Polynésie française, d'admettre qu'un Tupuna puisse transmettre quoique ce soit de mauvais comme, par exemple, une maladie(11). Au-delà de la prise en considération de la difficulté technique consistant à traduire en tahitien les travaux du CEPF (travail qui

(7) Ce serait toutefois une grave erreur que d'en conclure que la religion et le fonctionnement des institutions mènent, en Polynésie française, des existences séparées. Voir notamment sur ce thème: JOYAU, M. Les leçons des statuts spéciaux d'outre-mer: le cas de la Polynésie française. In: FIALAIRE, J. (Dir.). Liberté de culte, laïcité et collectivités territoriales. Paris: Litec, 2007. p. 199.

(8) Cette Académie a été créée par la Délibération n. 72-92 du 2 août 1972 /www.farevanaa.pf).

(9) Cette personnalité est en effet désignée par l'Académie tahitienne.

(10) ACADÉMIE TAHITIENNE, Dictionnaire Tahitien-Français. Fa'atoro parau Tahiti-Farani, Académie tahienne-Fare vana'a 1999. p. 239.

(11) Consultée sur cette question, l'Académie tahitienne a proposé "après consultation des académiciens", de traduire "maladie héréditaire" par ma'i tupuna et "maladie génétique" par ma'i 
au demeurant est réalisé par un service de traduction extérieur au CEPF(12)), c'est donc bien une préoccupation d'ordre éthique qui a conduit à prévoir la présence d'une personnalité représentant l'Académie tahitienne au sein du CEPF.

\subsection{Fonctionnement}

Le CEPF peut être saisi par le gouvernement et l'assemblée de la Polynésie française, mais également par un établissement public ou privé, une fondation et même une association à la condition que ces derniers aient pour objet principal la recherche, le développement technologique médical ou la promotion et la protection de la santé(13). En pratique, sur 22 avis rendus, les organes de la Polynésie française (COM) n'ont saisi le CEPF qu'à 5 reprises ${ }^{(14)}$, ce qui signifie que la collectivité territoriale polynésienne a finalement assez peu recours à ce comité. Tous les autres avis ont été rendus sur saisine du Centre Hospitalier Territorial (8 saisines), de l'Institut Louis Malardé(15) ( 7 saisines) ou de l'Université de la Polynésie française (2 saisines). Le CEPF dispose également d'un pouvoir d'auto-saisine ${ }^{(16)}$, mais il semble $e^{(17)}$ ne jamais l'avoir exercé.

La fréquence des réunions est réglementairement fixée à un minimum de deux par an ${ }^{(18)}$, mais en pratique ses réunions sont mensuelles. Les convocations et l'ordre du jour relèvent de son président, élu par le comité en son $\operatorname{sein}^{(19)}$.

L'instruction des dossiers s'opère de manière individuelle et collective. Chaque membre du comité reçoit, le plus souvent en pièces jointes à la convocation, les documents se rapportant aux questions inscrites à l'ordre du jour. Par ailleurs, les responsables des projets soumis pour avis sont invités par le comité afin qu'ils puissent apporter à ses membres toutes précisions

\footnotetext{
'ihitene, faisant ainsi œuvre créatrice pour que la langue polynésienne puisse suivre l'évolution de la vie moderne et de ses techniques (courrier électronique en réponse, daté 28 février 2006).

(12) V. infra, B.

(13) Délibération n. 99-209 APF du 18 novembre 1999 (art. 4, al. 1 et 2).

(14) Au sein du gouvernement, seuls les ministres de la santé (4 saisines) et de la culture, de l'enseignement supérieur et de la recherche (1 saisine) ont saisi le CEPF L'assemblée de la Polynésie française ne l'a quant à elle jamais fait.

(15) Doté du statut d'établissement public à caractère industriel et commercial (EPIC) le $1^{\mathrm{er}}$ janvier 2001, cet Institut concourt à la préservation de la santé, de l'hygiène publique et de l'environnement naturel de la Polynésie française (Délibération n. 2000-114 APF du 28 septembre 2000).

(16) Délibération n. 99-209 APF du 18 novembre 1999 (art. 4, al. 3).

(17) Les trois recommandations formulées par le CEPF ne font pas mention de l'auteur de la saisine, mais leur contenu ne permet pas de conclure à une auto-saisine dans le cadre de l'article 4 , alinéa 3.

(18) Délibération n. 99-209 APF du 18 novembre 1999 (art. 5, al. 1er).

(19) Délibération n. 99-209 APF du 18 novembre 1999 (art. 2, al. 2).
} 
nécessaires liées aux enjeux éthiques de leurs projets. Ces auditions sont rendues possibles par les textes qui permettent au CEPF d'inviter "toute personnalité qu'il jugera utile"(20).

Initialement, le comité ne pouvait valablement délibérer que si la moitié de ses membres était présente. Ce quorum a été abaissé à sept membres (sur quinze)(21), probablement en raison d'un absentéisme récurrent, même si la participation des membres - tous bénévoles - peut être considérée comme régulière ${ }^{(22)}$. L'adoption des avis se fait par ailleurs à la majorité des membres présents ${ }^{(23)}$, mais il est à noter qu'ils sont le plus souvent rendus à l'unanimité $(77,27 \%)$. De même, il n'est pas sans intérêt de souligner, la pratique étant semble-t-il différente au sein du CCNE, qu'aucun vote n'a lieu avant que chaque membre présent ait été invité à prendre la parole.

La forme des avis émis par le CEPF mérite que l'on s'y attarde. En effet, à la différence des avis du CCNE qui sont relativement longs et développent une réflexion et un point de vue éthiques sur un sujet donné, les avis du C.E.P.F. se caractérisent par leur brièveté et, sauf exception ${ }^{(24)}$, par une absence totale de motivation. L'avis est "Défavorable" ou "Favorable" et, dans ce dernier cas, il est le plus souvent assorti de réserves. De l'examen attentif de ces réserves ressortent quatre constantes:

1) le consentement libre, exprès et éclairé du donneur ou du sujet se prêtant à une étude biomédicale doit être recueilli préalablement, par l'initiateur de l'étude ;

2) chaque patient doit être informé, dans sa langue et de façon compréhensible, des résultats de la recherche, sauf refus exprimé par celui-ci;

3) le matériel biologique ne doit être destiné qu'à la recherche pour laquelle il a été prélevé, puis détruit au terme de celle-ci;

4) l'identité des personnes physiques et morales en charge de l'expérimentation doit être connue avec précision.

Les avis relatifs aux greffes de tissus et d'organes ont, quant à eux, donné lieu à des réserves particulières:

(20) Délibération n. 99-209 APF du 18 novembre 1999 (art. 5, al. 4). C'est ainsi, par exemple, qu'une réunion a été exclusivement consacrée, le 16 février 2004, à une rencontre avec P. $L$. Fagniez, rapporteur de la loi bioéthique à l'Assemblée nationale.

(21) Délibération n. 2004-13 APF du 22 janvier 2004 (art. 1ㄷ, III).

(22) Seules trois séances n'ont pas pu se tenir en raison d'un quorum insuffisant. La seule modification apportée au règlement intérieur du CEPF a malgré tout été relative à l'assouplissement des conditions permettant de déclarer un membre démissionnaire d'office.

(23) Délibération n. 99-209 APF du 18 novembre 1999 (art. 5, al. 3).

(24) V. infra, II. 
1) tout prélèvement ne peut être réalisé que sur des donneurs en état de mort encéphalique;

2) tout don d'organe doit respecter le principe de l'anonymat;

3) aucune transaction financière ne peut être exigée en contrepartie d'un don.

Le contenu de ces réserves peut surprendre dans la mesure où, en métropole, il figure dans des dispositions insérées dans le code de la santé publique ${ }^{(25)}$. Mais précisément, si ces réserves sont formulées par le CEPF, c'est qu'en vertu du principe dit "de spécialité législative"(26), ces dispositions du code de la santé publique ne s'appliquent pas en Polynésie française. En l'état actuel du droit positif, c'est donc le CEPF qui assure une régulation éthique en ces domaines, faute pour les organes compétents de la collectivité territoriale d'avoir réglementé ces questions ${ }^{(27)}$.

Les recommandations et avis sont rendus publics ${ }^{(28)}$. Sur cette question de la publicité, les dispositions réglementaires ne sont pas davantage précises. Le règlement intérieur du CEPF prévoit donc (article 15) que les avis et les recommandations sont rédigés en langues française et tahitienne ${ }^{(29)}$, qu'ils sont publiés au Journal Officiel de la Polynésie Française (JOPF) et portés à la connaissance du public par voie de communiqués ${ }^{(30)}$.

Enfin, tous les travaux du comité et l'ensemble de ses activités font l'objet d'un rapport annuel remis aux présidents de la Polynésie française, de l'assemblée de la Polynésie française, du Conseil économique, social et culturel ainsi qu'aux ministres chargés de la santé et de la recherche ${ }^{(31)}$.

(25) V. tout spécialement les Titre II ("Recherches biomédicales") du Livre ler ("Protection des personnes en matière de santé") et III ("Organes") et IV ("Tissus, cellules, produits du corps humain et leurs dérivés") du Livre II ("Don et utilisation des éléments et produits du corps humain") du code de la santé publique.

(26) Principe qui veut qu'une disposition législative ne s'applique en Polynésie française que si elle comporte une mention expresse d'applicabilité à cette C.O.M.

(27) Le CEPF n'a attiré l'attention des autorités locales sur ce point qu'à une seule reprise, et de manière très indirecte, dans son avis n. 21 ("Les questions qui sont à l'origine de sa saisine le conduisent en dernier lieu : ... à attirer l'attention de l'ensemble des autorités publiques sur le fait qu'il appartient à chacune d'elles de veiller, dans le champ de ses compétences, au respect de la loi et des exigences éthiques rappelées par le comité").

(28) Délibération n. 99-209 APF du 18 novembre 1999 (art. 6, al. 2).

(29) La rédaction en tahitien est assurée par le Service (territorial) de la traduction et de l'interprétariat, dans un délai variant de dix jours à trois mois.

(30) En pratique, ils ne sont pas publiés au JOPF et seuls les avis les plus importants sont publiés dans la presse locale.

(31) Délibération n. 99-209 APF du 18 novembre 1999 (art. 6, al. 1er). Un rapport (unique) a été établi pour les années 2001 et (une partie de) 2002. Un autre rapport a été établi pour l'année 2004. II semble que l'année 2003 n'ait pas fait l'objet d'un rapport annuel. 
Les autres modalités de détail du fonctionnement du CEPF sont fixées par son règlement intérieur(32), qu'il adopte à la majorité( ${ }^{(33)}$.

\section{ATTRIBUTIONS}

Les questions soumises au Comité d'éthique de la Polynésie française sont d'importance très inégale. Si certaines peuvent paraître anecdotiques sur le plan des principes éthiques ${ }^{(34)}$, la plupart ont permis au CEPF. de développer une réelle régulation en ce domaine $(A)$. Un avis mérite toutefois une attention particulière, l'avis $n .12$ relatif à la mise en place d'une banque d'ADN, en ce qu'il est symptomatique du caractère ambigu de cette institution qu'est le CEPF (B).

\subsection{Ediction de repères éthiques}

De manière ponctuelle, notamment par la formulation de réserves spécifiques, plusieurs avis ont permis au CEPF de proposer de véritables repères éthiques.

En ce qui concerne tout d'abord l'activité médicale proprement dite, le CEPF a ainsi été amené:

- à recommander, au profit des agents collecteurs ou de toute autre personne participant à la collecte de moustiques (et non cette fois au profit des patients) que soit recueilli sur un formulaire individuel leur consentement libre, exprès et éclairé sur le risque de transmission de la dengue (Avis n. 07);

- à recommander que les patients soient avertis de leur faculté de sortir à tout moment de l'expérimentation (Avis n. 09(35), 23 et 24);

- à rappeler que les médecins ne doivent être soumis à aucune pression, notamment à caractère économique (Avis n. 10) ${ }^{(36)}$.

(32) Délibération n. 99-209 APF du 18 novembre 1999 (art. 5, al. 5).

(33) Enfin, pour être complet, il faut encore ajouter que les moyens humain et matériel du comité sont extrêmement réduits. Le secrétariat est assuré par la direction de la santé (par une seule personne, responsable du bureau des affaires juridiques de la direction de la santé, remarquablement dévouée). II tient à la disposition des membres du comité une "documentation" (très peu abondante). Le CEPF n'a aucun budget.

(34) Tel est, sans doute, le cas du protocole de recherche relatif à l'évaluation de l'efficacité de la pratique régulière du karaté sur l'amélioration de la qualité de vie et les aptitudes physiques d'un groupe de quinquagénaires (Avis n. 16 du 30 octobre 2003).

(35) En raison, dans ce cas précis, du fait que la réalisation de l'étude imposait des contraintes spécifiques lourdes aux patients (appareillage, visites médicales fréquentes ...).

(36) L'avis précise que "leur convention avec le laboratoire doit être soumise pour avis au conseil de l'ordre des médecins. Les rémunérations ne seront pas calculées de manière proportionnelle au nombre de patients, de prestations ou de produits prescrits". 
Quelques avis permettent ensuite de mieux saisir le caractère "endémique" de l'éthique en Polynésie française.

- Tel est le cas des avis qui recommandent la traduction en langue tahitienne $e^{(37)}$ du formulaire de consentement du patient ou qui sont favorables sous cette réserve ${ }^{(38)}$;

- Tel est également le cas de l'avis, favorable, sous réserve que l'étude envisagée supprime "toute référence ethnique au profit d'une référence géographique" ${ }^{\text {(39). }}$. Ce point présente une importance capitale. En effet, de nombreuses études, notamment génétiques ${ }^{(40)}$, sont présentées comme devant être réalisées en fonction de l'origine ethnique, le plus souvent qualifiée de "polynésienne" ou de "tahitienne", des sujets concernés. Cependant, si du point de vue ethnologique on comprend évidemment la référence à la notion d'ethnie (de même que du point de vue biologique ${ }^{(41)}$ ou juridique ${ }^{(42)}$, on peut comprendre la référence à la notion de race), la terminologie devient précautionneuse quand il s'agit de corréler ethnie et biologie. Le risque est en effet de stigmatiser sur une population, dite "tahitienne" ou "polynésienne", des particularités génétiques pouvant être appréciées négativement. C'est d'ailleurs sans doute pour cette raison que le CEPF a émis, à l'unanimité, un avis défavorable au projet de recherche sur l'étude génétique des troubles bipolaires et schizophréniques en milieu insulaire ${ }^{(43)}$.

Avec ces deux derniers avis, on observe un passage de l'activité régulatrice du C.E.P.F., au sens d'activité normative consistant à édicter des "réglementations" (faute, encore une fois, pour les organes compétents de la collectivité territoriale d'avoir exercé leur compétence réglementaire) à une activité plus spécifiquement éthique, consistant à développer une réflexion et le cas échéant à émettre un point de vue sur un sujet donné. Cette tendance ressort plus particulièrement de deux avis rendus par le CEPF, alors qu'il

(37) Et, dans le cas d'une étude "qui touche plusieurs archipels, ... si possible dans une langue comprise par la patiente" (Avis n. 24).

(38) Avis n. 05, 07, 11, 13, 15 à 19 et 22 à 24.

(39) Avis n. 17.

(40) Recherches de gènes de susceptibilité à l'obésité, au diabète de type 2, au syndrome d'Alport (néphropathie - affection touchant le rein - héréditaire, souvent associée à une surdité et des anomalies oculaires), au cancer de la thyroïde, à des troubles cardiaques et à des troubles bipolaires et schizophréniques.

(41) MONOD, T. L'hippopotame et le philosophe. Actes Sud, 1993 (spéc. p. 45 à 50 : "Les races d'Afrique").

(42) Le Préambule de la Constitution du 27 octobre 1946 proclame, en son alinéa $1^{\text {er }}$, que tout être humain possède des droits inaliénables et sacrés "sans distinction de race". Quant au code pénal, il prévoit de nombreuses infractions en raison de distinctions opérées à partir de la race.

(43) Avis n. 14. Cette position a été adopté "considérant l'impact négatif que pourrait avoir cette étude sur la communauté, en raison principalement des difficultés à préserver la confidentialité" et "malgré l'intérêt de ce projet de recherche qui fait par ailleurs l'objet d'autres travaux dans le monde. le bénéfice escompté devant être mis en balance avec l'impact négatif". 
n'avait pas été saisi d'un projet de recherche. L'un est relatif à un avant-projet de délibération de l'assemblée de la Polynésie française concernant les modalités d'application des dispositions relatives à l'IVG ${ }^{(44)}$. L'autre est relatif à une pratique, développée depuis 2001 par quelques Polynésiens dialysés en attente d'une transplantation rénale ${ }^{(45)}$, qui consiste à se rendre en Chine pour se faire greffer, durant un séjour de 10 à 15 jours, un rein ... peut-être acheté à un donneur vivant ou prélevé sur un condamné à mort exécuté(46). Dans ces avis, le CEPF ne se déclare ni favorable, ni défavorable, il exprime une opinion ${ }^{(47)}$.

Cette dualité de l'activité du CEPF se retrouve, formulée en des termes sensiblement différents, dans les dispositions réglementaires qui lui sont applicables. L'article $1^{\text {er }}$ de la délibération du 18 novembre 1999 qui prévoit sa création dispose en effet, en son alinéa 2, que: "Ce comité a pour mission de donner des avis et recommandations sur les problèmes éthiques soulevées par les nouvelles technologies, la recherche et les progrès de la connaissance, dans les domaines de la biologie, de la médecine et de la santé", et en son alinéa 3, qu': "Il donne des avis sur tout projet de recherche biomédicale, qui lui est obligatoirement soumis". On notera au passage que le texte impose au CEPF de se prononcer sous la forme d'un "avis" dans cette dernière hypothèse, mais permet indistinctement le recours à un "avis" ou à une "recommandation" dans la première. En pratique, bien que le CEPF ait cherché à établir une distinction entre les avis et les recommandations ${ }^{(48)}$, force est de reconnaître qu'il n'attache aucune importance à cette typologie ${ }^{(49)}$.

\subsection{Un rôle parfois ambigu}

Saisi de cette question par le ministre de la santé, le CEPF a émis le 5 juin 2003 un avis favorable à la création d'une banque d'ADN en Polynésie

(44) Avis n. 06.

(45) Lassés d'attendre que des textes soient adoptés pour permettre la transplantation rénale en Polynésie française (où pour l'instant aucun texte ne régit le don d'organe) et ne souhaitant pas se rendre en Métropole où il leur faudra peut-être séjourner deux ans (temps moyen d'attente pour une greffe du rein).

(46) II ne semble pas, quand même, que des exécutions soient réalisées pour permettre la transplantation ... (Les Nouvelles de Tahiti, 10 juin 2005, p. 10).

(47) Peut-être est-il aussi possible de rattacher à cette tendance l'avis $n .20$ dans lequel le CEPF s'est déclaré défavorable à un projet de recherche en généalogie moléculaire visant à constituer une base de données "principalement destinée à relier des informations génétiques à des lignées généalogiques écrites" au motif, notamment, que "cet objectif est contraire aux règles de l'éthique" (formule que l'on peut quand même juger maladroite, dans la mesure où on ne voit pas bien, a priori, ce qu'elles sont ....).

(48) Dans son premier rapport annuel, on peut lire: "Un avis est rendu lorsqu'un projet de texte réglementaire est envisagé. Une recommandation est formulée lorsque certains éléments visent à préciser les modalités d'une étude ou d'une recherche en cours ou projetée" (page 2).

(49) Certains "Avis" ne comportent que des recommandations ( $n .05$ et 21) et parmi les rares "Recommandations", l'une d'elles ne comporte qu'un avis (n. 03-1) ... alors pourtant qu'il y est bien question d'un projet de recherche biomédicale. 
française: "sous la forme juridique d'un groupement d'intérêt économique garantissant son indépendance", "dans le respect des règles déontologiques applicables aux banques de données d'ADN" et "sous la réserve que le Comité d'éthique soit systématiquement saisi pour avis favorable préalablement à la mise à disposition de matériel génétique dans le cadre d'une recherche". Par ailleurs, dans ce même avis, le comité "recommande que lui soit communiqué pour avis l'ensemble du projet" de création de cette banque.

En quelques lignes, après en avoir quand même délibéré pendant neuf séances ${ }^{\left({ }^{50}\right)}$, le CEPF règle donc une question qui a fait l'objet, moins de trois mois plus tôt, d'un volumineux et très intéressant avis rendu par le CCNE Pourtant, comme le souligne cet avis du CCNE: "Les activités de collection et de traitement des échantillons biologiques d'origine humaine et des données d'information en résultant, plus particulièrement du fait de la recherche génétique, suscitent des interrogations éthiques majeures". En effet, si les "biobanques" ou "biothèques" constituent un atout considérable pour la recherche scientifique et soulèvent, de ce seul fait, d'importantes questions éthiques, "nul n'ignore que la science n'est pas la seule institution sociale à s'intéresser aux pratiques du recueil de données d'information relatives aux composantes génétiques des personnes. Les sociétés d'assurance ou les services d'enquête policière, par exemple ${ }^{(51)}$, sont particulièrement concernés par cet intérêt"(52).

II n'entre pas ici dans notre intention de porter une appréciation critique sur l'absence de position éthique fournie par l'avis du C.E.P.F. La référence au "respect des règles déontologiques applicables aux banques de données $A D N$ ' paraît en effet davantage relever de l'incantatoire que du réalisme. Si l'on en croit le C.C.N.E., il n'existerait pas vraiment de "règles déontologiques"(53) en la matière, puisque selon lui : "le premier pas à faire serait de définir les obligations communes régissant le statut du curateur (conservateur des échantillons et données), identiques que l'opérateur soit public, privé ou agisse en partenariat"(54). Par ailleurs, sur un plan éthique, il est permis de ne pas être convaincu du bien fondé de la position consistant à vouloir "garantir l'indépendance" d'une banque d'ADN ${ }^{(55)} \ldots$

(50) C'est pour cet avis que les délibérations ont été les plus nombreuses. Le plus souvent les avis sont rendus après deux délibérations (13 cas). Trois avis ont nécessité trois délibérations, quatre n'en ont nécessité qu'une. Un seul avis a été rendu après quatre délibérations.

(51) Car on ne saurait ignorer les relations financières (droits de propriété intellectuelle, dépôts de brevets en lien avec les recherches fondées sur ces banques ...) qui se nouent à propos des collections (V. le VII de l'avis n. 77, précité).

(52) Avis n. 77 du 20 mars 2003 sur les problèmes éthiques posés par les collections de matériel biologique et les données d'information associées : "biobanques", "biothèques", LES CAHIERS DU CCNE n. 38, p. 3, mars/avr. 2004.

(53) Au sens de code des devoirs à remplir, de "discours" sur ces devoirs /Le terme déontologie vient en effet "du grec deon (ce qu'il faut faire) et logos (discours)" (DINECHIN, O. de; DOMERGUE, M; DUMORTIER, F.-X.; PAREYDT, L. Liberté, Ioi, morale. Assas Éditions, 1992. p. 114)।.

(54) VII, 3 de l'avis précité.

(55) Dans son avis n. 77, le CCNE développe au contraire l'idée que "La banque doit ... être déclarée, éventuellement sujette à autorisation, en tout état de cause supervisée dans son fonctionnement" (III). 
En revanche, la prise en charge par le CEPF de la question juridique, et plus précisément statutaire, de la banque d'A.D.N. mérite que l'on s'y attarde. II est en effet incontestable que la mise en place d'une banque d'ADN suppose un "passage de l'éthique au droit"(56). Mais, comme le souligne le CCNE dans son avis précité: "Si la définition d'un statut pour la banque est le point de départ d'une réponse aux inquiétudes, elle n'est pas... le problème le plus difficile'(57) En outre, toujours selon le CCNE et à juste titre selon nous, il est de la responsabilité des pouvoirs publics "de prendre en charge le problème des banques et de mettre en ordre leur régime juridique"(58).

On ne peut donc que s'étonner de la position du Comité d'éthique de la Polynésie française.

Les termes de l'avis rendu par le CEPF ne permettent pas de savoir si la saisine du ministre en charge de la santé impliquait ou non que cette consultation porte également sur la forme juridique à donner à cette banque, mais il est raisonnablement permis d'en douter. Comment croire en effet que les organes de la collectivité territoriale polynésienne aient souhaité obtenir une "consultation juridique" d'un comité qu'ils savent fort bien ne pas avoir été constitué dans ce but et ne pas disposer de compétences juridiques particulières. En revanche, il n'est pas à exclure que le CEPF ait songé à la forme du groupement d'intérêt économique (GIE) en pensant ainsi garantir le bon fonctionnement et surtout l'indépendance de la banque d'ADN vis-àvis de tout pouvoir, politique, administratif ou économique ${ }^{(59)}$. A moins que ce ne soit en raison de l'influence d'une réflexion développée en ce sens par les services (juridiques ?) de cette collectivité territoriale ... Quoiqu'il en soit, le CEPF s'est emparé là d'une question qui relève de la compétence de la Polynésie française en sa qualité de COM et pour laquelle il n'est pas certain qu'il était lui même compétent, tant au sens de son aptitude juridique que de ses connaissances techniques.

Reste que la forme du GIE, condition de l'avis favorable du CEPF à la création d'une banque d'ADN, n'a pas été sans conséquence.

Cherchant à mettre en œuvre l'avis du CEPF (se croyant, à tort, liés par cet avis ?), les services territoriaux ont élaboré un projet de statuts d'un groupement d'intérêt économique qui a été soumis à d'éventuels partenaires ${ }^{(60)}$. Tous ont refusé de devenir membres du groupement d'intérêt économique (pour des raisons juridiques), proposant malgré tout de collaborer avec une banque d'ADN par voie de conventions. Quant au CEPF, il a rendu à trois

(56) 8 de l'avis précité.

(57) III de l'avis précité, in fine.

(58) VIII de l'avis précité.

(59) Préoccupation certainement fondée si on en croit A. W. du Prel, Banque d'ADN de Tahiti: étrange politique du gouvernement, TPM janvier 2001, p. 21.

(60) Association française contre les myopathies, Association Genethon III, Institut Louis Malardé, Université de la Polynésie française, Centre Hospitalier Territorial. 
reprises (avis 17, 18 et 23) des avis favorables pour des projets de recherche nécessitant des prélèvements génétiques, sous réserve que les chercheurs s'engagent à contrôler et à supprimer à la fin d'étude les prélèvements génétiques ${ }^{(61)}$. II continue(62) ainsi à s'opposer à toute forme de stockages, lesquels peuvent malgré tout présenter un avantage, au moins dans l'éventualité d'une nouvelle étude réalisée ultérieurement par les mêmes chercheurs, sur le même sujet... ${ }^{63)}$

En conclusion, le CEPF ne saurait être tenu pour une forme exotique des Comités de Protection des Personnes (CPP) $)^{(64)}$, non seulement parce qu'il n'est pas doté de la personnalité juridique ${ }^{(65)}$ et n'émet pas d'avis conforme $^{(66)}$, mais encore parce qu'à sa mission consistant à donner "des avis sur tout projet de recherche biomédicale, qui lui est obligatoirement soumis" s'ajoute celle, confiée en métropole au CCNE ${ }^{(67)}$, de donner "des avis et recommandations sur les problèmes éthiques soulevés par les nouvelles technologies, la recherche et les progrès de la connaissance, dans les domaines de la biologie, de la médecine et de la santé"(68).

Aussi, le CCNE étant qualifié d' "autorité indépendante" à l'article L. $1412-2$ du code de la santé publique ${ }^{(69)}$ et le CEPF étant quant à lui qualifié d' "organisme indépendant" à l'article 1르, alinéa 1 er de la délibération du 18 novembre 1999 précitée, il est sans doute possible de tenir le CEPF pour une Autorité Administrative Indépendante locale(70).

(61) Dans les avis 17 et 18, le CEPF précise que cette position est liée à "l'absence d'existence légale de la banque d'ADN en Polynésie française".

(62) Recommandation n. 2.

(63) Confrontés à une véritable situation de blocage due à la volonté de mettre en œuvre l'avis du CEPF, les pouvoirs publics semblent à présent s'orienter vers une solution qui consisterait à rattacher cette banque d'ADN au centre de transfusion sanguine, qui est un service de la direction de la santé, en élargissant ses missions.

(64) Ces comités ont été institués en remplacement des Comités Consultatifs de Protection des Personnes se prêtant à la Recherche Biomédicale (GAUDEMET, Y. Les comités consultatifs de protection des personnes dans la recherche biomédicale. CCPPRB Le Bilan juridique, JCP 1993-13653) par la loi n. 2004-806 du 9 août 2004 relative à la politique de la santé publique (MONNIER, $S$. Les Comités de protection des personnes: l'émergence d'une nouvelle catégorie de personnes publiques spécialisées?, RDP, p. 1519, 2005).

(65) Ce que sont les CPP (Art. L. 1123-1 du code de la santé publique).

(66) Art. L. 1121-4 du code de la santé publique (al. $1^{\text {er: }}$ "La recherche biomédicale ne peut être mise en œuvre qu'après avis favorable du comité de protection des personnes mentionné à l'article L. 1123-1 et autorisation de l'autorité compétente mentionnée à l'article L. 1123-12").

(67) "Le Comité consultatif national d'éthique pour les sciences de la vie et de la santé a pour mission de donner des avis sur les problèmes éthiques soulevés par les progrès de la connaissance dans les domaines de la biologie, de la médecine et de la santé et de publier des recommandations sur ces sujets" (art. 23, al. 19r de la Loi n. 94-654 du 29 juillet 1994 relative au don et à l'utilisation des éléments et produits du corps humain, à l'assistance médicale à la procréation et au diagnostic prénatal).

(68) V. supra.

(69) Dans sa rédaction issue de la Loi n. 2004-800 du 6 août 2004 relative à la bioéthique.

(70) Sur l'objection consistant à soutenir qu'une Autorité Administrative Indépendante ne saurait être qu'une institution de l'Etat, voir: JOYAU, M. La régulation éthique en Polynésie française. CAPP, n. 14, p. 32, spéc. pp. 43-44, 2006. 